\title{
A Randomized Controlled Trial to Compare Adaptive Support Ventilation and Pressure Support Ventilation for Weaning COPD Patients
}

\author{
Authors \\ Fayed AM*, Megahed MM*, El-Bourini MS* \\ *Department of Critical Care Medicine, Alexandria Main University Hospital, \\ University of Alexandria, Alexandria, Egypt
}

\begin{abstract}
Patients with COPD are frequently hospitalized for acute exacerbations (AECOPD), which may cause respiratory failure. Adaptive support ventilation $(A S V)$ is an automatic system of ventilation, where it determines target minute ventilation based on the principle proposed by Otis et al. Weaning with ASV shows promising results, mainly in post cardiac surgery patients.

Objective: Our study was designed to compare ASV with PSV in the weaning of AECOPD patients

Methods: The study was conducted on 60 mechanically ventilated AECOPD patients admitted to the Department of Critical Care Medicine, at the Alexandria Main University Hospital. Exclusion criteria included those with severe cardiac or neurological disease, those managed by non-invasive ventilation and those on tracheostomy tube. All patients were subjected on admission to complete history taking, complete physical examination and Laboratory investigations and were treated according to guidelines of treatment of AECOPD. At the time of weaning patients were randomly divided into two equal groups; Group A: patients weaned using ASV and Group B: patients weaned using PSV.

Results: Weaning duration was significantly shorter with ASV versus PSV [median (IQR) 24 (12-48) $h$ versus 72 (24-144) $h, p<0.001]$. Success rates were [(93.3\%) for ASV and (70\%) in PSV group B ( $p=$ $0.042)]$. Length of stay in the ICU was also significantly shorter with ASV ( $p=0.001)$.

Conclusion: ASV may be used in the weaning of AECOPD patients with the advantage of shorter weaning times and hospital stay.

Keywords: Acute exacerbation of COPD, Adaptive support ventilation, Intensive care unit, Pressure support ventilation, Work of breathing, weaning success.
\end{abstract}

\section{INTRODUCTION}

Patients with COPD are frequently hospitalized for acute exacerbations, most commonly in association with respiratory infections. The effect of these exacerbations on survival is unclear, with estimates varying widely. ${ }^{(1-4)}$

The Global Initiative for Chronic Obstructive Lung Disease (GOLD) - a report produced by the National Heart, Lung, and Blood Institute
(NHLBI) and the (WHO) defines an exacerbation of COPD as an acute increase in symptoms beyond normal day-to-day variation. ${ }^{(5,6)}$

PSV is commonly utilized and is the sole mode of mechanical ventilation used during the weaning process in, $21 \%$ of patients. ${ }^{(7)} \mathrm{PSV}$ can be used during a SBT and as a weaning mode. PSV used as the sole mode of mechanical ventilation during initial weaning attempts has been tested in two large randomised controlled trials. The study by 
Brochard et al ${ }^{(8)}$ involving 456 randomised patients determined that the use of PSV compared with SIMV and intermittent T-piece trials resulted in shorter duration of weaning. In 130 patients who had failed the initial SBT, Esteban et al ${ }^{(9)}$ reported that either one daily trial or multiple daily trials of unassisted, spontaneous breathing (Tpiece) more substantially reduced the duration of weaning than either SIMV or PSV.

Adaptive support ventilation (ASV), first described by Laubscher ${ }^{(10)}$, it relies on closedloop regulation of settings in response to changes in respiratory mechanics and spontaneous breathing, with wide-ranging, automated, pressure modes from pressure-controlled ventilation to pressure-support ventilation. ${ }^{(11-14)}$

Some studies have evaluated the use of ASV in weaning cardiac surgery patients and have shown a reduction in weaning time, a reduced need for arterial blood gas (ABG) analyses, and fewer ventilator adjustments. ${ }^{(15-18)}$

The use of ASV in patients with COPD has been described previously, ${ }^{(19,20)}$ but only one study reported the use of ASV as a weaning mode for chronically ventilated patients, some of whom had COPD. ${ }^{(21)}$

Our study was therefore designed to compare ASV with PSV in the weaning of AECOPD patients.

\section{MATERIALS AND METHODS \\ Patients}

This randomized controlled study was conducted on 60 mechanically ventilated AECOPD patients who were admitted to the Department of Critical Care Medicine in The Alexandria Main University Hospital. The study was approved by the medical ethics committee of Alexandria faculty of Medicine. An informed consent from patients' next of kin was obtained before enrollment to the study.

Inclusion criteria:

1. A diagnosis of AECOPD. ${ }^{(22)}$

2. Patients with APACHE II score of 15-30.
3. Patients being on mechanical ventilation for at least 24 hours because of hypoxemic and/or hypercapnic respiratory failure.

Exclusion criteria:

1. Mechanical ventilation for less than 24 hours (including self extubation or death).

2. Patients with a tracheostomy tube.

3. COPD patients with coexisting severe cardiac (except cor pulmonale due to COPD) or neurologic disease as it may prolong weaning for extrapulmonary reasons.

4. Patients managed using non-invasive ventilation before intubation.

Patients of the two groups were treated according to guidelines of treatment of AECOPD. ${ }^{(23-26)}$ All patients were orally intubated and mechanically ventilated using $\mathrm{Bi}$ PAP (Duo PAP). Initial settings were as follows: $P_{\text {INSP }}$ achieving a tidal volume of $8 \mathrm{~mL} / \mathrm{kg}$, back-up respiratory rate (RR) 12-14 breaths/min, and positive end-expiratory pressure (PEEP) of 3-5 $\mathrm{cmH}_{2} \mathrm{O}$. Inspiratory oxygen fraction $\left(\mathrm{F}_{\mathrm{I}} \mathrm{O}_{2}\right)$ was titrated to obtain an arterial oxygen saturation $\left(\mathrm{SaO}_{2}\right) 90 \%$. Sedation was achieved with midazolam and/or fentanyl.

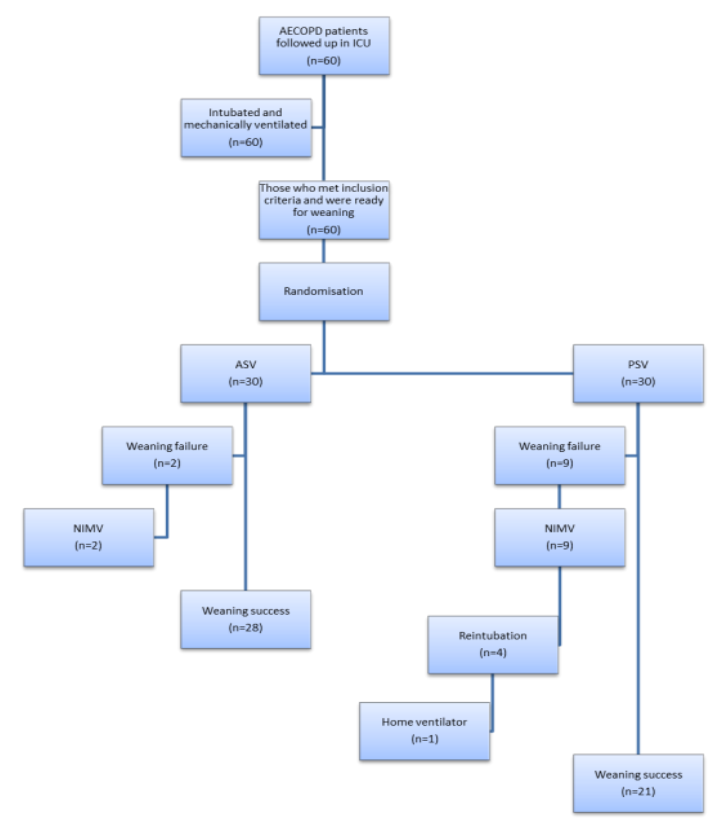

FIGURE 1. Flow chart of patients during the study. AECOPD: Acute exacerbation of chronic obstructive pulmonary disease; ICU: intensive care unit; ASV: adaptive support ventilation; 
PSV: pressure support ventilation; NIMV: noninvasive mechanical ventilation.

When weaning from mechanical ventilation was decided, according to weaning criteria as defined as reversing the cause of mechanical ventilation, hemodynamic stability, heart rate $<120, \mathrm{RR}<35$, $\mathrm{pH}>7.35$, tidal volume $\left(\mathrm{V}_{\mathrm{T}}\right)>5 \mathrm{ml} / \mathrm{kg}$, minute volume $<10 \mathrm{~L} / \mathrm{min}$, PEEP $<5 \mathrm{cmH}_{2} \mathrm{O}, \mathrm{P}_{\mathrm{a}} \mathrm{O}_{2}>60$ mmHg with $\mathrm{F}_{\mathrm{i}} \mathrm{O}_{2}<0.4$, and $\mathrm{P}_{\mathrm{a}} \mathrm{O}_{2} / \mathrm{F}_{\mathrm{i}} \mathrm{O}_{2}>150^{(27,28)}$, the studied patients were randomly enrolled using the sealed envelope method into two equal groups as shown in figure 1 .

\section{ASV description}

ASV provides automatic ventilation in which minute volume is controlled via a $V_{\mathrm{T}} / \mathrm{RR}$ combination based on respiratory mechanics. ASV assumes that the adequate ventilation of normal subjects is $100 \mathrm{ml} / \mathrm{min}$ per $\mathrm{kg}$ of body weight. In patients unable to trigger a breath, the ventilator generates pressure controlled breaths, automatically adjusting inspiratory pressure and timing to achieve the target $\mathrm{V}_{\mathrm{T}}$ and RR. In patients who are able to trigger a breath, the ventilator generates pressure support breaths, automatically adjusting the level of support pressure to achieve the target $\mathrm{V}_{\mathrm{T}}$, and delivers additional pressurecontrolled breaths if the patient's RR is below the target RR. The target $\mathrm{V}_{\mathrm{T}} / \mathrm{RR}$ combination is based on the equation by Otis et al. ${ }^{(29)}$, which determines an RR that minimizes work of inspiration for a clinician-set minute volume, based on the time constant of the respiratory system. The time constant is estimated on a breath-by-breath basis by the expiratory time constant (RCexp) obtained from the expiratory flow-volume curve. ${ }^{(30,31)}$

\section{Weaning protocols}

After randomisation, the BiPAP (Duo PAP) mode was stopped and the two weaning modes (ASV and PSV) were allocated randomly using sealed envelopes. Weaning and extubation were performed by the critical care physicians who were working in the ICU.
ASV Group: weaned using ASV present in the Hamilton G-5 ventilator in the following steps: ${ }^{(32)}$

a) Setting the ideal body weight in $\mathrm{Kg}$.

b) Setting the $\mathrm{M}_{\mathrm{V}}$ at $100 \mathrm{ml} / \mathrm{kg} \mathrm{PBW}$.

c) ASV detected the patient's effort and automatically weaned the mandatory breath rate when the patient was ready to assume a portion of the $\mathrm{V}_{\mathrm{m}}$ requirement through spontaneous breathing independent of the target $\mathrm{M}_{\mathrm{V}}$.

d) If the patient did not have spontaneous breaths, and the ABGs were accepted, reduction of $\% \mathrm{~V}_{\mathrm{m}}$ by 10 to $20 \%$ will be tried to encourage spontaneous breathing.

e) When extubation criteria were met ${ }^{(33)}$; Adequate gas exchange [Adequate arterial partial pressure of oxygen: $\left[\mathrm{PaO}_{2} / \mathrm{FIO}_{2}\right]$ ratio > 150-200, appropriate $\mathrm{pH}(\mathrm{pH}$ 27.25) and arterial partial pressure of carbon dioxide during spontaneous ventilation], $R R<35$, Vital capacity $>$ than $10 \mathrm{~mL} / \mathrm{kg}$, NIF > -20, Tidal Volume > $5 \mathrm{~mL} / \mathrm{kg}$, Minute ventilation $<10 \mathrm{~L} / \mathrm{min}$, Ability to protect airway [Appropriate level of consciousness, adequate airway protective reflexes (cough, swallow, vocal cord movement), adequate managed secretions], Hemodynamic stability, Nutritional status allowing for respiratory muscle strength, extubation was attempted directly without SBT.

PSV Group: weaned using PSV in the following steps: ${ }^{(34)}$

a) Starting at maximum PSV level (level that attains $\mathrm{RR}<20$ with $\mathrm{V}_{\mathrm{T}}$ of $8 \mathrm{ml} / \mathrm{kg}$ ).

b) Decrease PSV by $5 \mathrm{cmH}_{2} \mathrm{O}$.

c) If no signs of intolerance were evident for 4 hours trial, the PSV was decreased by another $5 \mathrm{cmH}_{2} \mathrm{O}$ for another 4 hours.

d) With any signs of intolerance, defined as $\mathrm{RR}>35, \mathrm{~S}_{\mathrm{a}} \mathrm{O}_{2}<90 \%, \mathrm{HR}>140$, systolic BP $>180$ or $<90 \mathrm{mmHg}$, anxiety and diaphoresis, the patient was returned to the previous level for the next 4 hours. 
e) If unable to tolerate, the patient was fully rested until the next day when the process began again.

f) Once the patient was able to sustain 7 $\mathrm{cmH}_{2} \mathrm{O} \mathrm{PSV}$ without signs of intolerance for 4 hours, extubation was attempted.

Post-extubation failure occurring within the first $48 \mathrm{~h}$ was defined as $\mathrm{pH}<7.35$, an increase in arterial carbon dioxide tension of $15 \mathrm{mmHg}$ from the value just prior to extubation, RR 24 breaths/min and accessory muscle use. NIMV trial with a full face mask was performed in these patients using the same ventilator in NIMV mode to avert re-intubation. ${ }^{(35-37)}$ Patients who could not tolerate NIMV or showed impairment in their clinical status (unable to protect airway, inability to remove secretions, cardiac instability or loss of consciousness) or blood gas analysis $(\mathrm{pH}<7.25$ and $\mathrm{PaO}_{2}, 60 \mathrm{mmHg}$ while receiving NIMV) were re-intubated. These patients were considered as having failed weaning irrespective of their outcomes using NIMV.

\section{Outcomes and definitions}

Weaning duration was the primary outcome, defined as the time from randomisation to extubation. Weaning success was defined as independence from mechanical ventilation (invasive or noninvasive) $\geq 48 \mathrm{~h}$ after extubation. Secondary outcomes were duration of mechanical ventilation and length of stay (LOS) in the ICU and the hospital. Duration of mechanical ventilation was defined as the time from the initiation of mechanical ventilation support to the permanent cessation of any form of ventilatory support (invasive or noninvasive). Duration of IMV before was defined as the time of IMV from intubation to the time of randomisation. LOS in the ICU was defined as the time from admission to the ICU until discharge or death.

\section{Statistical Analysis: ${ }^{(38)}$}

A sample size of 30 patients per each group was calculated using Medcalc program version 8.1.0.0 at a power of $>80 \%$ and level of significance $(\boldsymbol{p})$ of 0.05. Data were analyzed using SPSS software package version 18.0 (SPSS, Chicago, IL, USA). Quantitative data were expressed using median and Interquartile range (IQR), while Qualitative data were expressed in frequency and percent. Qualitative data were analyzed using Chi-square test also exact tests such as Fisher exact was applied to compare the two groups. Not normally distributed quantitative data was analyzed using Mann Whitney test for comparing the two groups. Pearson coefficient was used to analyze correlation between any two variables. A $\boldsymbol{p}$-value of $\leq 0.05$ was considered significant.

\section{RESULTS}

The ASV and PSV groups were demographically similar at the time of randomisation. Factors that could affect weaning, such as the severity of patients assessed by APACHE II score, need of sedation and respiratory parameters, were also comparable between the two groups (table 1). Both groups were similar as regards arterial blood gases before extubation (table 2).

As regards the outcome measures in this study, success rate was $(93 \%)$ with two cases $(6.7 \%)$ of weaning failure in ASV group, while the success rate was $(70 \%)$ with nine cases $(30 \%)$ of weaning failure in PSV group B ( $p=0.042)$ (table 3). Two patients in the ASV group and nine in the PSV group could not tolerate extubation and received NIMV. Four patients in the PSV needed reintubation and one of them was discharged later on with a home ventilator.

Weaning duration was significantly shorter with ASV versus PSV [median (IQR) 24 (12-48) h versus 72 (24-144) h, p < 0.001].

\begin{tabular}{|c|c|c|c|}
\hline \multirow[t]{2}{*}{ TABLE 1} & \multirow{2}{*}{$\begin{array}{l}\text { aracteristic data } b \\
\text { ASV }\end{array}$} & \multirow{2}{*}{$\begin{array}{l}\text { ore randomisation } \\
\text { PSV }\end{array}$} & \multirow[b]{2}{*}{ p-value } \\
\hline & & & \\
\hline Subject n & 30 & 30 & 1 \\
\hline Age yrs & $55(49-74)$ & $61(50-73)$ & 0.05 \\
\hline Males & $25(83.3)$ & $24(80)$ & 0.73 \\
\hline APACHE II & $20.5(15-30)$ & $23.5(19-30)$ & 0.08 \\
\hline pH & $7.4(7.35-7.41)$ & $7.4(7.36-7.41)$ & 0.16 \\
\hline $\mathrm{PaCO}_{2} \mathrm{mmHg}$ & $55(34-58)$ & $55(36-60)$ & 0.67 \\
\hline $\mathrm{HCO}_{3} \mathrm{mEq} / \mathrm{L}$ & $32(23-40)$ & $30(22-39)$ & 0.62 \\
\hline $\mathrm{PaO}_{2} / \mathrm{FiO}_{2}$ & $221(177-406)$ & $235(177-406)$ & 0.75 \\
\hline $\begin{array}{l}\text { Duration of MV before } \\
\text { randomisation } h\end{array}$ & $36(24-120)$ & $48(24-120)$ & 0.09 \\
\hline 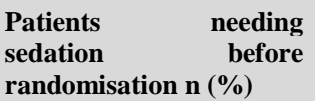 & $10(33.3)$ & $10(33.3)$ & 1 \\
\hline
\end{tabular}


Data are presented as median (interquartile range) or $\mathrm{n}(\%)$, unless otherwise stated. ASV: adaptive support ventilation; PSV: pressure support ventilation; APACHE: Acute Physiology and Chronic Health Evaluation; $\mathrm{PaCO}_{2}$ : arterial carbon dioxide tension; $\mathrm{HCO}_{3}$ : bicarbonate level; $\mathrm{PaO}_{2} / \mathrm{FiO}_{2}$ : arterial oxygen tension/inspiratory oxygen fraction; MV: mechanical ventilation.

Weaning duration for the two groups expressed as Kaplan- Meier curves are shown in figure 2. Total duration of mechanical ventilation was significantly shorter with ASV versus PSV [median (IQR) 50 (36-168) h versus 120 (48-192) $\mathrm{h}, \mathrm{p}<0.001]$. LOS in the ICU was also shorter with ASV compared with PSV [median (IQR) 4 (2.5-9) days versus 6 (3-11) days, $\mathrm{p}<0.001]$. LOS in the hospital was also shorter with ASV compared with PSV [median (IQR) 5 (3-9) days versus 8 (4-12) days, $\mathrm{p}<0.001$ ] (table 3).

\begin{tabular}{llll} 
TABLE 2 & \multicolumn{2}{l}{ Arterial blood gases before extubation } & \\
& ASV & PSV & $\begin{array}{l}\text { p- } \\
\text { value }\end{array}$ \\
\hline Subject n & 30 & 30 & 1 \\
$\mathbf{p H}$ & $7.4(7.35-7.51)$ & $7.38(7.35-7.5)$ & 0.38 \\
$\mathbf{P a C O}_{2} \mathbf{~ m m H g}$ & $49(36-62)$ & $55(43-69)$ & 0.22 \\
$\mathbf{H C O}_{\mathbf{~ m E q}} / \mathbf{L}$ & $35(22-43)$ & $36.5(31-45)$ & 0.08 \\
$\mathbf{S a O}_{\mathbf{2}} \mathbf{\%}$ & $96(91-98)$ & $96(94-99.5)$ & 0.46 \\
$\mathbf{P a O}_{2} / \mathbf{F i O}_{2}$ & $238(153-406)$ & $227(194-457)$ & 0.32 \\
\hline
\end{tabular}

Data are presented as median (interquartile range) or $\mathrm{n}(\%)$, unless otherwise stated. ASV: adaptive support ventilation; PSV: pressure support ventilation; $\mathrm{PaCO}_{2}$ : arterial carbon dioxide tension; $\mathrm{HCO}_{3}$ : bicarbonate level; $\mathrm{SaO}_{2}$ arterial oxygen saturation; $\mathrm{PaO}_{2} / \mathrm{FiO}_{2}$ : arterial oxygen tension/inspiratory oxygen fraction.

\begin{tabular}{|c|c|c|c|}
\hline \multirow{2}{*}{$\begin{array}{l}\text { TABLE } 3 \\
\text { Outcomes }\end{array}$} & \multicolumn{2}{|c|}{ f ASV and PSV groups } & \multirow[b]{2}{*}{ p-value } \\
\hline & ASV & PSV & \\
\hline Subject n & 30 & 30 & 1 \\
\hline Weaning duration $h$ & $24(12-48)$ & $72(24-144)$ & 0.001 \\
\hline Weaning failure & $2(6.7)$ & $9(30)$ & 0.042 \\
\hline Duration of MV h & $60(36-168)$ & $120(48-192)$ & 0.001 \\
\hline LOS in ICU days & $4(2.5-9)$ & $6(3-11)$ & 0.001 \\
\hline LOS in hospital days & $5(3-9)$ & $8(4-12)$ & 0.001 \\
\hline
\end{tabular}

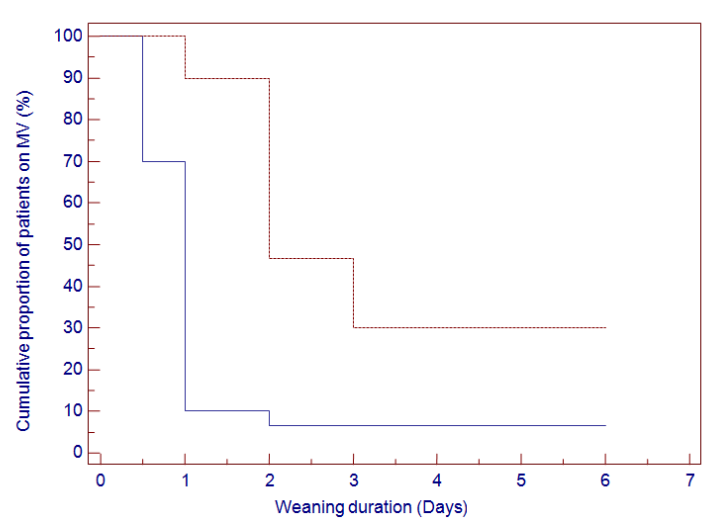

FIGURE 2. Duration of weaning expressed as a Kaplan-Meier curve in the adaptive support ventilation (- - and pressure support ventilation (-----) groups. MV: mechanical ventilation. Log rank test, $\mathrm{p}=0.001$.

\section{DISCUSSION}

The major finding of this study was that, when compared with PSV in the weaning process of COPD patients, ASV was associated with a shorter weaning duration.

With similar results, Kirakli et al ${ }^{(39)}$ reported a significant shorter duration of weaning with ASV than PSV in AECOPD patients [median (IQR) 24 (20-62) h versus 72 (24-144) h, p = 0.041]. ICU stay was also shorter in ASV group [median (IQR) 11 (6-15) days versus 13 (8-14) days, $\mathrm{p}=$ $0.5]$ but this difference was not statistically significant, while results from our study had significantly shorter LOS in ICU [median (IQR) 4 (2.5-9) days versus 6 (3-11) days, $\mathrm{p}<0.001]$.

Of the few studies evaluating ASV in weaning, most were performed in post-cardiac surgery patients where the mean extubation time was $<6$ h.

Sulzer et al (15) reported shorter duration of intubation and mechanical ventilation with ASV than synchronized intermittent mandatory ventilation (SIMV) in post-operative coronary bypass patients. Cassina et al ${ }^{(40)}$ used ASV when weaning 155 cardiac surgery patients; $86 \%$ were extubated within $6 \mathrm{~h}$ and the mean time to extubation was $3.6 \mathrm{~h}$. In a randomised controlled trial, Petter et al (16) compared ASV with SIMV+PSV when weaning 45 cardiac surgery patients and found that the duration of mechanical ventilation and the need for changing the ventilator settings were reduced with ASV. These findings suggest that ASV could be used for fast and early extubation after post-cardiac surgery. However, none of these studies included COPD patients.

Randomised controlled studies and subsequent meta-analysis indicated that spontaneous breathing trial (SBT) with T-piece or PSV are equally effective and both superior to SIMV, depending in the most part on the experience of the staff with a particular method ${ }^{(8,9,41,42)}$. Tassaux et al ${ }^{(19)}$ compared ASV and SIMV+PSV patient ventilator interactions in ten patients, three of whom had acute exacerbations of COPD; they concluded that ASV could provide the same 
minute ventilation with less muscle load and patient-ventilator dyssynchrony when compared with SIMV+PSV. In addition, similar levels of minute ventilation and $\mathrm{V}_{\mathrm{T}}(\mathrm{mL}) /$ patients $(\mathrm{kg})$ ratio were achieved with ASV.

Esteban et al ${ }^{(43)}$ reported weaning success rates of $70 \%$ for PSV and $63 \%$ for SBT. Their study was performed on a heterogeneous population, but $20 \%$ of the patients enrolled had COPD. Our study found weaning success rates of $93.3 \%$ and $70 \%$ for ASV and PSA respectively, similar to those in the literature.

\section{Limitations of the study}

Some studies concerning the weaning procedures suggested that SBT's with T-piece were superior to SIMV and PSV ${ }^{(9)}$, while others showed that gradual reduction of pressure support was superior in patients who failed a 2-h SBT with T-piece ${ }^{(8)}$. Further studies are needed to assess the feasibility of ASV in difficult to wean patients who fail SBTs with a T-piece.

Patients with previous use of NIMV were not included in the study. However, in most situations, most patients with AECOPD are intubated after failure of NIMV. This limits the generalization of the results to all intubated patients with AECOPD.

This single centre study reflects experience of a single ICU. With 30 patients in each group we were able to detect a reduction of 1.78 days in the weaning duration $(\mathrm{p}<0.001)$. Multicentric, higher powered studies with large sample sizes could more accurately assess the generalizability of these results to different centers and patient populations.

The lack of ICU staff prevented us from recording the number of interventions and ABG sampling needed for each group. Further studies are needed to determine the other potential benefits of ASV as patient comfort and respiratory mechanics, such as work of breathing and pressure time product with different weaning modes.

\section{CONCLUSIONS}

In light of our results we recommend that ASV may be used as a weaning mode in mechanically ventilated AECOPD patients, with the advantage of shorter weaning duration. Further studies with large sample sizes are needed to investigate the potential advantages of this mode in the weaning period and ICU stay of different patient groups.

\section{STATEMENT OF INTEREST}

None declared.

\section{REFERENCES}

1. Gunen H, Hacievliyagil SS, Kosar F, Gulbas G, et al. Factors affecting survival of hospitalized patients with COPD. Eur Respir J 2005; 26:234

2. Patil, SP, Krishnan, JA, Lechtzin, N, Diette, GB. In-hospital mortality following acute exacerbations of chronic obstructive pulmonary disease. Arch Intern Med 2003; 163:1180.

3. Seneff MG, Wagner DP, Wagner RP, Zimmerman JE, et al. Hospital and 1-year survival of patients admitted to intensive care units with acute exacerbation of chronic obstructive pulmonary disease. JAMA 1995; 274:1852.

4. Breen, D, Churches, T, Hawker, F, Torzillo, PJ. Acute respiratory failure secondary to chronic obstructive pulmonary disease treated in the intensive care unit: a long term follow up study. Thorax 2002; 57:29.

5. Snider, GL. Nosology for our day: its application to chronic obstructive pulmonary disease. Am J Respir Crit Care Med 2008; 167:678.

6. Global strategy for the diagnosis, management, and prevention of chronic obstructive pulmonary disease: Executive summary 2013. Global Initiative for Chronic Obstructive Lung Disease (GOLD). Available at: www.goldcopd.org. 
7. Boles JM, Bion J, Connors A, Herridge M, et al. Weaning from mechanical ventilation. Eur Respir J 2007; 29: 1043.

8. Brochard L, Rauss A, Benito S, et al. Comparison of three methods of gradual withdrawal from ventilatory support during weaning from mechanical ventilation. Am J Respir Crit Care Med 1994; 150: 896-903.

9. Esteban A, Frutos F, Tobin MJ, et al. A comparison of four methods of weaning patients from mechanical ventilation. Spanish Lung Failure Collaborative Group. N Engl J Med 1995; 332: 345-50.

10. Laubscher TP, Heinrichs W, Weiler N, Hartmann G, et al. An adaptive lung ventilation controller. IEEE Trans Biomed Eng 1994; 41:51-9.

11. Laubscher TP, Frutiger A, Fanconi S, Brunner JX. The automatic selection of ventilation parameters during the initial phase of mechanical ventilation. Intensive Care Med 1996; 22(3):199-207.

12. Brunner JX. Principles and history of closed-loop controlled ventilation. Respir Care Clin N Am 2001; 7(3):341-62.

13. Brunner JX, Iotti GA. Adaptive support ventilation (ASV). Minerva Anestesiol 2002; 68(5):365-68.

14. Campbell RS, Branson RD, Johannigman JA. Adaptive support ventilation. Respir Care Clin N Am 2001; 7(3):425-40.

15. Sulzer CF, Chiolero R, Chassot PG, et al. Adaptive support ventilation for fast tracheal extubation after cardiac surgery: a randomized controlled study. Anesthesiology 2001; 95: 1339-45.

16. Petter AH, Chiolero RL, Cassina T, et al. Automatic "respirator/weaning" with adaptive support ventilation: the effect on duration of endotracheal intubation and patient management. Anesth Analg 2003; 97: 1743-50.

17. Dongelmans DA, Veelo DP, Paulus F, et al. Weaning automation with adaptive support ventilation: a randomized controlled trial in cardiothoracic surgery patients. Anesth Analg 2009; 108: 565-71.

18. Gruber PC, Gomersall CD, Leung P, et al. Randomized controlled trial comparing adaptive-support ventilation with pressureregulated volume-controlled ventilation with auto mode in weaning patients after cardiac surgery. Anesthesiology 2008; 109: 81-7.

19. Tassaux D, Dalmas E, Gratadour P, et al. Patient-ventilator interactions during partial ventilatory support: a preliminary study comparing the effects of adaptive support ventilation with synchronized intermittent mandatory ventilation plus inspiratory pressure support. Crit Care Med 2002; 30: 801-7.

20. Arnal JM, Wysocki M, Nafati C, et al. Automatic selection of breathing pattern using adaptive support ventilation. Intensive Care Med 2008; 34: 75-81.

21. Linton DM, Renov G, Lafair J, et al. Adaptive support ventilation as the sole mode of ventilatory support in chronically ventilated patients. Crit Care Resusc 2006; 8: $11-4$.

22. Asia-Pacific COPD Roundtable Group. Global Initiative for Chronic Obstructive Lung Disease strategy for the diagnosis, management and prevention of chronic obstructive pulmonary disease: an AsiaPacific perspective. Respirology 2005; 10: 9-17.

23. Celli BR. Standards for the optimal management of COPD. Chest 1998; 113:283-7.

24. American Thoracic Society. Standards for the diagnosis and care of patients with chronic obstructive pulmonary disease. American Journal of Respiratory and Critical Care Medicine 1995; 152:77-120.

25. Peter B. Bach, Cynthia Brown, Sarah E. Gelfand, and Douglas C. McCrory. Management of acute exacerbations of chronic obstructive pulmonary disease: a summary and appraisal of published 
evidence. Annals of Internal Medicine 2001; 134(7):600-20.

26. Pauwels RA, Löfdahl CG, Postma DS, Tattersfield AE, et al. Global strategy for the diagnosis, management, and prevention of chronic obstructive pulmonary disease. NHLBI/WHO Global Initiative for Chronic Obstructive Lung Disease (GOLD) Workshop summary. American Journal of Respiratory and Crit Care Med 2001; 163(5):1256-76.

27. Krieger, BP, Ershowsky, PF, Becker, DA, Gazeroglu, HB. Evaluation of conventional criteria for predicting successful weaning from mechanical ventilatory support in elderly patients. Crit Care Med 1989; 17:858.

28. Tobin MJ, Perez W, Guenther SM, Semmes BJ, et al. The pattern of breathing during successful and unsuccessful trials of weaning from mechanical ventilation. Am Rev Respir Dis 1986; 134:1111.

29. Otis AB, Fenn WO, Rahn H. Mechanics of breathing in man. J Appl Physiol 1950; 2: 592-607.

30. Brunner JX, Laubscher TP, Banner MJ, et al. Simple method to measure total expiratory time constant based on the passive expiratory flow-volume curve. Crit Care Med 1995; 23: 1117-22.

31. Lourens MS, van den Berg B, Aerts JG, et al. Expiratory time constants in mechanically ventilated patients with and without COPD. Intensive Care Med 2000; 26: $1612-18$.

32. Branson R, Johannigman J, Cambell R, Davis K. Closed-loop Mechanical Ventilation. Respiratory Care 2002; 47(4):427-35.

33. American Association for Respiratory Care (AARC). Removal of the endotracheal tube--2007 revision \& update. Respir Care 2007 Jan; 52(1):81-93.

34. Adapted from University of Virginia Health System MICU weaning protocol (Available @:www.nursingvirginia.edu/weaningproto c-ol.html).

35. Nava S, Hill N. Non-invasive ventilation in acute respiratory failure. Lancet 2009; 374: 250-9.

36. Hilbert G, Gruson D, Portel L, et al. Noninvasive pressure support ventilation in COPD patients with post extubation hypercapnic respiratory insufficiency. Eur Respir J 1998; 11: 1349-53.

37. Ferrer M, Valencia M, Nicolas JM, et al. Bernadich early noninvasive ventilation averts extubation failure in patients at risk: a randomized trial. Am J Respir Crit Care Med 2006; 173: 164-70.

38. Puri BK. SPSS in Practice, an Illustrated Guide: Arnold, London, 2002; pp 320.

39. Kirakli C, Ozdemir I, Ucar Z.Z, Cimen P, et al. Adaptive support ventilation for faster weaning in COPD: a randomised controlled trial. Eur Respir $J$ 2011; 38:774-80.

40. Cassina $\mathrm{T}$, Chiolero R, Mauri R, et al. Clinical experience with adaptive support ventilation for fast-track cardiac surgery. $J$ Cardiothorac Vasc Anesth 2003; 17: 5715.

41. Vitacca M, Vianello A, Colombo D, et al. Comparison of two methods for weaning patients with chronic obstructive pulmonary disease requiring mechanical ventilation for more than 15 days. Am J Respir Crit Care Med 2001; 164: 225-30.

42. Hess D. Ventilator modes used in weaning. Chest 2001; 120: Suppl.6, 474-6.

43. Esteban A, Alia I, Gordo F, et al. Extubation outcome after spontaneous breathing trials with $\mathrm{T}$-tube or pressure support ventilation. The Spanish Lung Failure Collaborative Group. Am J Respir Crit Care Med 1997; 156: 459-65. 